\title{
Rural Women's Comprehension of Multimedia CD on Compost Pit
}

\author{
Yeshwant Menareia*, SnehlataMaheshwari and Dhriti Solanki \\ Department of Home Science Extension and Communication Management, College of \\ Community and Applied Science, Maharana Pratap University Of Agriculture and \\ Technology, Udaipur, Rajasthan, India \\ *Corresponding author
}

\section{Keywords}

Rural women, Multimedia CD, Compost pit

\section{Article Info}

Accepted:

17 March 2019 Available Online: 10 April 2019

\section{A B S T R A C T}

Communication is essential for all human relations. Mass media thought to have powerful, uniform and direct influence on individual. Multimedia application can present information in variety of forms (text, graphics, animation, audio, video) involving the use of more of our senses. It better explain a subject matter to the learner because it enhances the comprehension capability of the learner. The present study was planned to develop multimedia $\mathrm{CD}$ on Compost Pit and field-test for perception and comprehension by rural women. The study was conducted in two phases. In first phase multimedia CD was developed and evaluated by ten experts on various criteria's i.e. overall purpose served, content covered, interest orientation, visuals used and audio recording. The visuals were further evaluated on the various sub aspects organization and layout, color, visual clarity, attention catching, self-explanatory, continuity in messages, tuning with commentary and overall comprehension. The audio recording was evaluated on the aspects as language, commentary, content clarity, voice, continuity of messages, pace and speed of narration, length and time of narration, overall length of programme, music and overall comprehension. All criteria's according to expert's suggestions, voice was modified. In phase second, the multimedia CD was field tested with thirty-five rural women of Panerion ki Madri of Udaipur district. Only post test experimental research design was used for collecting data through interview technique. The major findings of the present study were2. Perception and comprehension of developed multimedia CD on Environmental Sanitation was found to be very good as all the message of the six components except two messages were understood by 80 per cent respondents. The messages were:-Compost Pit Use of compost improves soil fertility, Compost increases crop production, Provide all the required micro-nutrient needed by soil, Prevents environmental pollution, Reduce the requirement of chemical fertilizer, Makes ploughing easier, Increase water absorption capacity of the soil, Requirement of raw materials for preparing compost, Constructing compost pit in shade, Process of filling raw material in compost pit, Checking of readiness of compost. Only two messages i.e. taking wastewater to soak pit and using sanitary latrines were perceived and comprehended by 71.42 per cent respondents. 3. Overall comprehension of developed multimedia $\mathrm{CD}$ was found to be very good as more than 88.40percent respondents could comprehend all the eleven messages of Compost Pit. 


\section{Introduction}

Communication is essential for all human relations. Rapid advances in communication technology specially in electronic and satellite communication has changed the media scenario and proliferation on new information and media technologies has brought about fundamental changes in several spheres of human activity- life styles, entertainment, work culture, modes of communication and has also influenced social and cultural values in the society.

Communication with rural people is a difficult and challenging task as the vast majority of them are illiterate, conservative with limited exposure to audio visual aids. The communication with these people requires communication device and channels that cut through these barriers and transfer scientific information to them for better quality of life. Therefore the present study was planned to develop multimedia $\mathrm{CD}$ on Compost Pit in rural areas by rural women with following specific objectives:-

To develop multimedia CD on "Compost Pit" To field-test the multimedia $\mathrm{CD}$ for comprehension of messages on "Compost Pit" by rural women.

\section{Materials and Methods}

The study was conducted in two phases, in first phase the multimedia CD was developed on "Compost Pit" by the investigator under the guidance of major advisor. For developing multimedia $\mathrm{CD}$, in-depth literature was reviewed and necessary information was gathered. After gathering subject matter information, the audio and video script were prepared followed by a storyboard then Captured live or created situation with the help of digital handy cam and graphics were prepared on computer as well as scanned. The commentary was recorded on the computer with the help of software i.e. sound forge 7.0 at the end audio and video was synchronized and editing was done with the help of video editor (editing software). The developed CD was evaluated by ten experts panel on the five major criteria's i.e. overall purpose served, content covered, interest orientation, visuals used and audio recording. The visuals were further evaluated on the various sub aspects such as organization and layout, color, visual clarity, attention catching, self-explanatory, continuity in messages, tuning with commentary and overall comprehension. The audio recording was evaluated on the aspects as language, commentary, content clarity, voice, continuity of messages, pace and speed of narration, length and time of narration, overall length of programme, music and overall comprehension. The evaluation was done on 3 point continuum as good, average and poor with scores of 3,2 and 1 respectively. The multimedia $\mathrm{CD}$ was modified as per the analysis of expert evaluation and then pre tested with seven rural women.

In second phase modified multimedia $C D$ was field tested for its comprehension with purposively selected thirty-five illiterate rural women. The respondents were selected from the village Panerion ki Madri of Girwa Panchayat Samiti of Udaipur District. Only post test experimental research design was used. Interview technique was used for data collection. The collected data were classified, tabulated and analyzed with frequency and percentage.

\section{Results and Discussion}

\section{Development of multimedia CD}

As per the objective multimedia $\mathrm{CD}$ on Compost Pit was developed by the investigator following the script. The 
developed multimedia $\mathrm{CD}$ on Compost Pit was rated good by the experts with the overall mean weighted score was 2.50 based on all the criteria's of evaluation. As in-depth evaluation of Compost Pit by experts on various criteria's was found good or near to good with MWSs ranging between 2.25 - 3 except for voice where MWS was 2.12 with suggestion regarding pronunciation of few words hence words in voice were revised.

\section{Comprehension of multimedia CD on Compost Pit by rural women}

More than sixty percent of the respondents $(65.71 \%)$ were illiterate, majority of respondents $(64.57 \%)$ belonged to schedule caste and schedule tribe.

Comprehension is the ability of the learner to understand what they see and hear. The effectiveness of any communication material depends on the comprehension of that material by the clientele group. In the present study comprehension was studied for messages of Compost Pit conveyed through developed multimedia $\mathrm{CD}$. The respondents were exposed to multimedia $\mathrm{CD}$ pogramme on Compost Pit. Eleven key messages were identified in the programme and comprehension of these messages by respondents was studied (Table 1 and 2).

Table.1 In depth evaluation of compost pit under various aspects by experts

\begin{tabular}{|c|l|c|}
\hline S.No. & \multicolumn{1}{|c|}{ Aspects } & Mean weighted scores \\
\hline $\mathbf{1 .}$ & Purpose & $\mathbf{2 . 8 7}$ \\
\hline $\mathbf{2 .}$ & Content & $\mathbf{2 . 8 7}$ \\
\hline $\mathbf{3 .}$ & Interest orientation & $\mathbf{2 . 7 5}$ \\
\hline $\mathbf{4 .}$ & Visual Assessment: & \\
\hline & Organization layout & $\mathbf{2 . 7 5}$ \\
\hline & Color & $\mathbf{2 . 6 2}$ \\
\hline & Visual clarity & $\mathbf{2 . 3 7}$ \\
\hline & Attention catching & $\mathbf{2 . 6 2}$ \\
\hline & Self explanatory & $\mathbf{2 . 7 5}$ \\
\hline & Continuity of messages & $\mathbf{2 . 6 2}$ \\
\hline & Tuning with commentary & $\mathbf{2 . 8 7}$ \\
\hline & Overall comprehension & $\mathbf{3}$ \\
\hline & Audio Assessment & $\mathbf{3}$ \\
\hline & Language & $\mathbf{2 . 7 5}$ \\
\hline & Commentary & $\mathbf{2 . 5}$ \\
\hline & Content Clarity & $\mathbf{2 . 1 2}$ \\
\hline & Voice & $\mathbf{2 . 8 7}$ \\
\hline & Continuity of messages & $\mathbf{3}$ \\
\hline & Pace and speed of narration & $\mathbf{3}$ \\
\hline & Length and time of narration & $\mathbf{3}$ \\
\hline & Overall length of programme & $\mathbf{3}$ \\
\hline & Music & $\mathbf{2 . 8 7}$ \\
\hline & Overall comprehension & $\mathbf{2 . 5}$ \\
\hline & Overall Mean Weighted & \\
\hline & Score & \\
\hline & & \\
\hline & & \\
\hline & &
\end{tabular}


Table.2 Percentage distribution of respondents by their comprehension of messages related to compost pit

\begin{tabular}{|c|l|c|}
\hline S.No. & \multicolumn{1}{|c|}{ Messages } & Percentage \\
\hline 1. & Use of Compost Pit improves soil fertility & $\mathbf{1 0 0 . 0 0}$ \\
\hline 2. & Compost increases crop production & $\mathbf{1 0 0 . 0 0}$ \\
\hline 3. & Provide all the required micronutrients needed by soil & $\mathbf{8 2 . 8 5}$ \\
\hline 4. & Prevents environmental pollution & $\mathbf{9 1 . 4 2}$ \\
\hline 5. & Reduces the requirement of chemical fertilizers & $\mathbf{8 5 . 7 1}$ \\
\hline 6. & Makes ploughing easier & $\mathbf{1 0 0 . 0 0}$ \\
\hline 7. & Increase water absorption of the soil & $\mathbf{9 1 . 4 2}$ \\
\hline $\mathbf{8 .}$ & Requirement of raw material for preparing compost & $\mathbf{1 0 0 . 0 0}$ \\
\hline 9. & Construction of compost pit in shade & $\mathbf{8 5 . 7 1}$ \\
\hline 10. & Process of filling raw material in compost pit & $\mathbf{8 8 . 5 7}$ \\
\hline 11. & Checking readiness of Compost & $\mathbf{8 2 . 8 5}$ \\
\hline
\end{tabular}

Out of eleven messages four messages were comprehended by all the respondents as Usage of Compost Pit improves soil fertility, Compost increases crop production, Makes Ploughing easier and Requirement of raw material for preparing compost. The messages of prevents environmental pollution, needed micro nutrients for soil and increase water absorption of the soil, construction of compost pit, process of filling raw material in compost pit and checking readiness of Compost were comprehended by 91.42 and 80 per cent respondent respectively.

These findings reflect that majority of the respondents were able to understand the messages related to compost pit. The reason for such findings could be that the programme designed was having shots from rural background with synchronized audio recording following Hindi language, using easy to understand words. The programme was also designed to run at normal pace, which helped the rural woman to understand and grasp the messages.

The findings get decisive support from the study of Bhatnagar (1993) regarding visual perception and comprehension of flip book on guinea worm" indicated that when flipbook was used with instructions the messages were comprehended fully by tribal women while without instruction they were not able to visualize correctly incomplete and half picture for e.g. half man and half object.

\section{References}

Bhatnagar, K., (1993). "Visual Perception and Comprehension of the Flip Book on Gunieaworm by Tribal Men and Women of Udaipur District," Unpublished M.Sc. Thesis, College of Home Science, Udaipur, RAU, Bikaner.

Desai, K.V. (1999). "Relative Effectiveness of Instructional Media in Teaching Science to Student of Satandard VIII," the educational review 105(9):156157.

Gupta, P., and Kothari, K., (1990). "A Study on Comprehension of Posters on Health and Sanitation, Project Report (Sponsored by SWACH), R.A.U., Udaipur campus

Gupta, V.S. (1995). "Communication Technology, Media Policy and National Development Concept 
Publishing Company, New Delhi, P. 94-98.

Purushothaman, S., Sundaram, S. and Stella, T.S. (1992). "Video assisted instruction. In English language teaching," Journal of Educational Research and Extension, 28(4): 176181.

\section{How to cite this article:}

Yeshwant Menareia, SnehlataMaheshwari and Dhriti Solanki. 2019. Rural Women's Comprehension of Multimedia CD on "Compost Pit". Int.J.Curr.Microbiol.App.Sci. 8(04): 2520-2524. doi: https://doi.org/10.20546/ijcmas.2019.804.293 